\title{
A trajetória do Programa Nacional de Alimentação Escolar no período de 2003-2010: relato do gestor nacional
}

\author{
The trajectory of the Brazilian School Nutrition Program \\ between 2003 and 2010: report of the national manager
}

${ }^{1}$ Coordenação Geral do Programa Nacional de Alimentação Escolar, Fundo Nacional de Desenvolvimento da Educação. SHS 05 BLOCO B - Anexo do FNDE, ASA SUL. 70315-000 Brasilia DF. albaneide.peixinho@ fnde.gov.br

\begin{abstract}
The scope of this paper is to study the report of the manager of the Brazilian School Nutrition Program (PNAE), with special emphasis on the period from 2003 to 2010. It is a critical essay based on a review of the literature and the official data. It was revealed that the program spent 954.2 million Brazilian reals in 2003 to assist 37.3 million students, and in 2010 the total resources increased to 3 billion Brazilian reals with 45.6 million students attended. Other important advances were the broadening and strengthening of the role of the School Nutrition Councils and the regulatory strategies of nutritionists as Accountable Technicians. Law No. 11.947/2009 gave a new impetus to the PNAE, extending the program to the entire basic public education grid and youths and adults, and recommending that $30 \%$ of the funds transferred from the FNDE should be used to acquire products from small farmers. The progress in technical and operational criteria seeking greater flexibility, efficiency and effectiveness in the management of the Program is clear for all to see. It is hoped that these advances will translate into effective improvement in food and nutrition conditions for schoolchildren.
\end{abstract}

Key words Brazilian School Nutrition Program, Pubic policies, Food and nutrition, School meals
Resumo O objetivo deste estudo é realizar um relato do gestor nacional do Programa Nacional de Alimentação Escolar (PNAE), com ênfase no período de 2003 a 2010. Trata-se de ensaio crítico baseado em revisão da literatura e em dados oficiais. Em relação ao volume de recursos financeiros e ao número de alunos atendidos, observou-se que, em 2003, o Programa executou um total de 954,2 milhões de reais para atender 37,3 milhões de alunos, ao passo que em 2010, o total de recursos passou a ser de 3 bilhões de reais para um total de 45,6 milhões de alunos atendidos. Outros avanços importantes foram os estímulos para a ampliação e o fortalecimento do papel dos Conselhos de Alimentação Escolar e as estratégias normativas para as ações do nutricionista como Responsável Técnico. A Lei no 11.947/2009 fez o PNAE avançar ainda mais, estendendo o programa para toda a rede pública de educação básica e de jovens e adultos, e recomendando que $30 \%$ dos repasses do FNDE sejam investidos na aquisição de produtos da agricultura familiar. São evidentes os avanços nos critérios técnicos e operacionais visando maior flexibilidade, eficiência e eficácia na gestão do PNAE. Espera-se que tais avanços possam se traduzir em melhoria das condições de alimentação e nutrição dos escolares.

Palavras-chave Programa Nacional de Alimentação Escolar, Políticas Públicas, Alimentação e Nutrição, Alimentação Escolar 


\section{Introdução}

O Programa Nacional de Alimentação Escolar (PNAE) caracteriza-se como a política pública de maior longevidade do país na área de segurança alimentar e nutricional, sendo considerado um dos maiores, mais abrangentes e duradouros programas na área de alimentação escolar do mundo ${ }^{1-3}$.

São evidentes os avanços que o PNAE conquistou ao longo das últimas décadas, sobretudo a partir de 1995 e, mais particularmente, no período de 2003 a 2010. De acordo com dados estatísticos oficiais, no período de 1995 a 2010, observase uma importante ampliação do PNAE, tanto em termos de alocação de recursos financeiros, como de cobertura populacional. Entre 1995 a 2010, o PNAE ampliou sua cobertura populacional de 33,2 milhões para 45,6 milhões de escolares, enquanto a alocação de recursos financeiros passou de 590,1 milhões para 3 bilhões de reais ${ }^{4}$.

Outros avanços importantes dizem respeito ao estabelecimento de critérios técnicos e operacionais visando maior flexibilidade, eficiência e eficácia na gestão do Programa, tais como os estímulos para a ampliação e o fortalecimento do papel dos Conselhos de Alimentação Escolar (CAEs) no controle social ${ }^{5,6}$, as estratégias normativas para as ações do nutricionista como Responsável Técnico ${ }^{7,8} \mathrm{e}$ mesmo a instituição dos Centros Colaboradores em Alimentação e Nutrição do Escolar (CECANE) $)^{9}$.

A sanção da Lei no 11.947 , de 16 de junho de 2009, por sua vez, trouxe novos avanços para o PNAE, como a extensão do programa para toda a rede pública de educação básica e de jovens e adultos, e a recomendação de que no mínimo $30 \%$ do repasse do FNDE sejam investidos na aquisição de produtos da agricultura familiar.

Em detrimento de sua abrangência e relevância no cenário nacional e internacional do campo das políticas públicas de alimentação e nutrição, ainda são escassas as publicações científicas sobre a trajetória histórica, a abrangência, a eficiência e a eficácia do PNAE. Neste sentido, ressalta-se a pertinência do presente artigo, cujo propósito é realizar um relato e uma avaliação do gestor nacional do PNAE, com ênfase nas ações desenvolvidas no período de 2003 a 2010.

Trata-se de um ensaio crítico realizado com base em revisão da literatura e em dados oficiais fornecidos pelo Fundo Nacional de Desenvolvimento da Educação/Ministério da Educação (FNDE/MEC), instituição responsável pela gestão do Programa no contexto nacional. Espera- se com isso propiciar divulgação e visibilidade das ações desenvolvidas pelo PNAE/FNDE, visando a melhoria da gestão do PNAE e, por consequência, melhoria das condições de alimentação e nutrição dos escolares brasileiros.

\section{A Trajetória do PNAE: \\ breve histórico dos anos 1930 a 2002}

As primeiras ações governamentais direcionadas à alimentação e nutrição no Brasil datam da década de 1930, quando a fome e a desnutrição foram reconhecidas como graves problemas de saúde pública no país. Após vários inquéritos alimentares constatou-se que tanto a classe operária como a população como um todo tinha condições alimentares precárias. O Governo brasileiro tomou, então, algumas medidas que poderiam, em princípio, influenciar a alimentação dos trabalhadores, sendo a primeira a criação do salário mínimo em $1^{\circ}$ de maio de 1940 . A segunda medida foi a criação, em agosto de 1940, do Serviço de Alimentação da Previdência Social (SAPS) destinado à melhoria dos hábitos alimentares do trabalhador brasileiro e que pode ser considerada a primeira política pública de alimentação do país. Na sequência, em 1945, foi criada a Comissão Nacional de Alimentação (CNA) e, quase uma década depois, criou-se a Campanha Nacional da Merenda Escolar, contando com a ajuda de doações internacionais de alimentos ${ }^{10-13}$.

É importante mencionar a decisiva atuação de Josué de Castro, na década de 1950, como deputado federal e Presidente do Conselho Executivo da Organização das Nações Unidas para Agricultura e Alimentação (FAO), que visava despertar a consciência mundial para o problema da fome e da miséria e promover projetos que evidenciassem que a fome poderia ser vencida $\mathrm{e}$ abolida pela ação e vontade dos atores sociais ${ }^{14}$.

Os anos de 1955 até 1970 foram de total e nítido predomínio da participação de organismos internacionais no PNAE. Pode-se dizer que o mesmo teve uma primeira etapa, iniciada na década de 1950, caracterizada pela presença de recursos provenientes do United Nations Children's Fund (UNICEF) chamado no Brasil de FISI - Fundo Internacional de Socorro à Infância. A década de 1960 pode ser vista como uma segunda etapa do programa, marcada fortemente pela presença de alimentos provenientes dos Estados Unidos da América, entre os quais do Programa "Alimentos para a Paz", financiado pela United States Agency for International Development (USAID) e do Programa Mundial de Alimentos (PMA) da Organi- 
zação das Nações Unidas (ONU), os quais forneciam a quase totalidade dos gêneros consumidos pelos escolares brasileiros ${ }^{10,11,13}$.

Nestas décadas apresenta-se, pela primeira vez, a estrutura de um programa de alimentação escolar, sob a responsabilidade do governo federal e com abrangência nacional. Entretanto, a cobertura do programa ainda era pouco efetiva e a regularidade do fornecimento da alimentação era baixa. Neste primeiro momento, não havia a preocupação com a adequação cultural ou com a aceitabilidade dos alimentos oferecidos ${ }^{10}$.

A década de 1970 foi marcada pela participação prioritária de gêneros comprados nacionalmente, com o consequente crescimento de várias empresas nacionais fornecedoras de alimentos, configurando uma terceira etapa desse processo. A partir daí, os alimentos formulados como sopas e mingaus - produzidos pelas indústrias alimentícias, passam a ter presença marcante na cesta de produtos da alimentação escolar ${ }^{10,11,13}$.

Em 1976 ocorre a integração da Campanha Nacional de Alimentação Escolar (CNAE) ao II Programa Nacional de Alimentação e Nutrição (II PRONAN), quando seu objetivo passou a ser proporcionar suplementação alimentar aos préescolares e escolares do primeiro grau matriculados nos estabelecimentos de ensino público, por meio do fornecimento de uma refeição de valor nutricional equivalente a $15 \%$ das recomendações nutricionais diárias durante o ano letivo. Em 1979, o Programa passou a efetivamente se denominar Programa Nacional de Alimentação Escolar (PNAE). Assim, entre 1976 a 1984, O PNAE se constituiu em uma das diretrizes do II PRONAN, coordenado pelo Instituto Nacional de Alimentação e Nutrição (INAN), autarquia vinculada ao Ministério da Saúde. O II PRONAN propôs programas de suplementação alimentar dirigidos aos trabalhadores, ao grupo materno-infantil e aos escolares, privilegiando as regiões mais pobres. Pretendeu, concomitantemente, introduzir um conjunto de inovações naquela política, entre elas: integrar os vários ministérios; estimular a produção de produtos básicos; interferir na cadeia de abastecimento; adquirir gêneros alimentícios do pequeno produtor; e garantir preços mais competitivos ${ }^{15}$ (MS/INAN, 1976). Algumas avaliações do II PRONAN apontaram, dentre os fatores que contribuíram para o menor êxito das suas ações, a falta de apoio político e orçamentário, seu uso clientelístico e a falta de pontualidade das ações implementadas ${ }^{10,11,13,16}$.

O ano de 1988 foi marcante para o tema da alimentação escolar no país. A Constituição Bra- sileira, promulgada em 1988, no inciso VII do artigo 208, passou a assegurar o direito universalizado à alimentação escolar a todos os alunos de ensino fundamental da rede pública, a ser garantido pelos governos federal, estaduais e municipais ${ }^{17}$. Ressalta-se, também, o importante processo de renovação das ideias emergentes da atuação do movimento social, em um tempo de retomada da abertura política.

A promulgação da Lei no 8.913 de 1994, a qual possibilitou a administração da alimentação escolar de forma descentralizada, foi um dos grandes avanços ocorridos neste Programa, pois permitiu racionalizar a logística e os custos de distribuição dos produtos, além de viabilizar o oferecimento de uma alimentação condizente com o hábito alimentar da população nas diferentes localidades do país ${ }^{18}$. Ressalta-se que as compras institucionais descentralizadas, apesar das inúmeras limitações, abriram a possibilidade de inserção da pequena empresa, do comércio local, do pequeno produtor agrícola e da pecuária local neste mercado institucional.

Em 1997, a Fundação de Assistência ao Estudante (FAE) e suas representações estaduais (REFAE), órgãos gestores do PNAE nos contextos federal e estaduais, respectivamente, foram extintas e seus programas foram incorporados pelo Fundo Nacional de Desenvolvimento da Educação (FNDE), autarquia federal vinculada ao Ministério da Educação (MEC), que apresenta como principal atividade a assistência financeira a projetos e programas do ensino básico das escolas públicas ${ }^{4}$.

Em 1999, inicia-se uma nova modalidade de repasse de recursos financeiros do Governo Federal, não mais por convênios, mas por transferência automática. Todos os municípios, Distrito Federal (DF) e estados do país passam a receber os recursos para aquisição de gêneros alimentícios $^{19}$. Em 2000, o Governo Federal estabelece que, para repassar as verbas para os estados, o DF e os municípios, é necessária a existência obrigatória dos Conselhos de Alimentação Escolar $(\mathrm{CAE})^{20}$.

A partir de 2000, os instrumentos legais que determinavam a constituição e as atribuições dos CAES no processo de gestão e execução do PNAE sofreram diversas reedições por necessidade de formalidades constitucionais, porém sem alterações de essência. A Medida Provisória 1979-19 de 02 de junho de $2000^{20}$ e suas reedições estabeleceu composição, número e atribuições para o CAE, órgão deliberativo, fiscalizador e de assessoramento do PNAE/FNDE, que passou a ter a seguinte composição: 
"I - um representante do Poder Executivo, indicado pelo Chefe desse Poder; II - um representante do Poder Legislativo, indicado pela Mesa Diretora desse Poder; III - dois representantes dos professores, indicados pelo respectivo órgão de classe; IV - dois representantes de pais de alunos, indicados pelos Conselhos Escolares, Associações de Pais e Mestres ou entidades similares; V - um representante de outro segmento da sociedade local" 20 .

Outra característica importante a ser destacada foi a definição do mandato de dois anos para os membros do CAE, podendo os mesmos serem reconduzidos uma única vez ${ }^{20}$.

Ainda de acordo com essa Medida Provisória $^{20}$, as competências do CAE ficaram assim definidas:

"I - acompanhar a aplicação dos recursos federais transferidos à conta do PNAE; II - zelar pela qualidade dos produtos, em todos os níveis, desde a aquisição até a distribuição, observando sempre as boas práticas higiênicas e sanitárias; III - receber, analisar e remeter ao FNDE, com parecer conclusivo, as prestações de contas do PNAE encaminhadas pelos Estados, pelo Distrito Federal e pelos Municípios".

Em relação à evolução do volume de recursos financeiros executados e o número de alunos atendidos pelo PNAE ao longo do período de 1995 a 2002, de acordo com a Tabela 1, observa-se que, em1995, o Programa executou um total de 590,1 milhões de reais para atender 33,2 milhões de alunos, ao passo que em 2002, o total de recursos passou a ser de 848,6 milhões de reais para um total de 36,9 milhões de alunos atendidos ${ }^{4}$.

\section{O PNAE no período 2003-2010: um balanço oficial}

A partir de 2003, com o início do Governo Lula, instituiu-se no país a Estratégia Fome Zero, visando ao enfrentamento das questões relativas à fome por meio da integração de vários programas e políticas relacionados à assistência social, à transferência de renda e às ações de natureza estruturante, como a geração de emprego e renda, a reforma agrária e outras ${ }^{21}$.

Para o PNAE, avanços importantes foram verificados a partir desse período. Dentre estes destacam-se a revisão e o estabelecimento de critérios técnicos e operacionais visando maior flexibilidade, eficiência e eficácia na gestão do Programa, tais como os estímulos para a ampliação e o fortalecimento do papel dos CAE no controle social $^{4}$ e as estratégias normativas para as ações do nutricionista como Responsável Técnico ${ }^{7,8}$.
Tabela 1. Distribuição dos recursos financeiros executados (em milhões de reais) e do número de alunos atendidos pelo Programa Nacional de Alimentação Escolar (PNAE) no período de 1995 a 2010.

\begin{tabular}{ccc}
\hline Ano & $\begin{array}{c}\text { Recursos financeiros } \\
\text { (em milhões de R\$) }\end{array}$ & $\begin{array}{c}\text { Alunos atendidos } \\
\text { (em milhões) }\end{array}$ \\
\hline 1995 & 590,1 & 33,2 \\
1996 & 454,1 & 30,5 \\
1997 & 672,8 & 35,1 \\
1998 & 785,3 & 35,3 \\
1999 & 871,7 & 36,9 \\
2000 & 901,7 & 37,1 \\
2001 & 920,2 & 37,1 \\
2002 & 848,6 & 36,9 \\
2003 & 954,2 & 37,3 \\
2004 & 1.025 & 37,8 \\
2005 & 1.266 & 36,4 \\
2006 & 1.500 & 36,3 \\
2007 & 1.520 & 35,7 \\
2008 & 1.490 & 34,6 \\
2009 & 2.013 & 47,0 \\
2010 & 3.034 & 45,6 \\
\hline
\end{tabular}

Fonte: http://www.fnde.gov.br/index.php/ae-dados-estatisticos

Em relação ao nutricionista, ressalta-se que a partir de 2003, pela primeira vez verificou-se a inserção de um nutricionista na coordenação geral do programa dentro da sua esfera de gestão federal, ou seja, junto ao FNDE. Assim sendo, o PNAE passa a reafirmar que a responsabilidade técnica pela alimentação escolar nos Estados, no Distrito Federal, nos Municípios e nas escolas federais cabe ao nutricionista. As atribuições do nutricionista como responsável técnico do Programa vão desde a análise do perfil nutricional dos escolares atendidos para elaboração de cardápios e listas de compras, a realização de ações educativas em alimentação e nutrição que perpassem pelo currículo escolar ${ }^{7,8,22}$.

Vale destacar que o número de nutricionistas responsáveis técnicos pelo PNAE sofreu uma transformação significativa, pois em 2003, havia $12 \%$ desses profissionais atuando nos estados e municípios e em 2011 a abrangência é de 82\% dos municípios do Brasil ${ }^{4}$.

No ano de 2006, foi realizada pela Coordenação Geral do PNAE/FNDE a Pesquisa Nacional de Cardápios executados pelos estados e municípios brasileiros. Essa investigação possibilitou a análise dos alimentos e nutrientes ofertados pelas creches e escolas públicas brasileiras, das cinco regiões, inclusive indígenas e quilombolas. A referida pesquisa embasou as alterações na le- 
gislação que rege o PNAE quanto à elaboração dos cardápios, com a obrigatoriedade da inclusão da oferta mínima de três porções de frutas e/ ou hortaliças por semana (200g/semana), pois os resultados mostraram que $41 \%$ e $16 \%$ dos cardápios não apresentavam nenhum tipo de fruta ou hortaliça na semana, respectivamente ${ }^{6}$.

Frente ao perfil nutricional dos escolares no Brasil, com a crescente prevalência de sobrepeso e obesidade, o PNAE se apresenta como uma estratégia de promoção da alimentação saudável, tendo em vista a obrigatoriedade da oferta de frutas e hortaliças, proibição de bebidas de baixo valor nutricional, como refrigerantes e sucos em pó, e restrição de alimentos com alta quantidade de gordura, sal e açúcar ${ }^{6}$.

No bojo das inúmeras construções conceituais que foram acontecendo ao longo do histórico do Programa, sobretudo a partir da orientação do governo federal explicitada na estratégia Fome Zero ${ }^{21}$, a alimentação escolar começou a adquirir um caráter mais efetivamente relacionado ao contexto do processo ensino-aprendizagem e assumir a dimensão de prática pedagógica, de ação educativa, visando à promoção da saúde e da segurança alimentar e nutricional ${ }^{4}$.

Para tanto, foram eleitos alguns princípios norteadores da execução do programa junto aos estados e municípios: equidade, participação social, universalidade, sustentabilidade/continuidade, compartilhamento de responsabilidades, direito humano à alimentação adequada e respeito aos hábitos e tradições regionais ${ }^{4}$.

A grande conquista para o PNAE, sem dúvida, veio com a publicação da Lei no 11.947 , de 16 de junho de $2009^{5}$. Conquista esta, fruto de um processo intersetorial no Governo Federal e de ampla participação da sociedade civil por meio do Conselho Nacional de Segurança Alimentar e Nutricional (CONSEA). Avança quando dispõe sobre alimentação escolar e não somente sobre um Programa. Universaliza o PNAE para toda educação básica, ou seja, da educação infantil ao ensino médio, além dos jovens e adultos; define a educação alimentar e nutricional como eixo prioritário para o alcance dos objetivos do Programa; fortalece a participação da comunidade no controle social das ações desenvolvidas pelos Estados, DF e Municípios; formaliza a garantia da alimentação aos alunos mesmo quando houver suspensão do repasse dos recursos por eventuais irregularidades constatadas na execução do PNAE5 5 .

Prevê ainda o apoio ao desenvolvimento sustentável, com incentivos para aquisição de gêneros alimentícios diversificados, produzidos lo- calmente, respeitando a sazonalidade, a cultura e a tradição alimentar. Para isso, foi definida a obrigatoriedade da aquisição de no mínimo $30 \%$ dos recursos financeiros repassados pelo PNAE em gêneros alimentícios diretamente da Agricultura Familiar e do Empreendedor Familiar ou suas organizações, priorizando os assentamentos da reforma agrária, as comunidades tradicionais indígenas e as comunidades quilombolas. E também que os alimentos orgânicos e/ou agro ecológicos deverão ser priorizados, sempre que possível, nos cardápios da alimentação escolar ${ }^{5}$.

A Lei $n^{0} 11.947 / 2009^{5}$ abriu um precedente histórico em relação às compras institucionais, garantindo que aproximadamente 01 bilhão de reais por ano, apenas com os recursos transferidos pelo FNDE para o PNAE (dados para 2011), sejam adquiridos diretamente desse público. Essa Lei ainda possibilitou ao gestor público dispensar o processo licitatório, por meio de outro instrumento, o "Chamada Pública", normatizado pelo FNDE por meio da Resolução no 38/20096.

Nessa questão específica, ao analisar os documentos de Prestação de Contas do PNAE encaminhados pelos Estados, DF e Municípios, para o ano de 2010 ( $1^{\circ}$ ano de obrigatoriedade da compra da Agricultura Familiar), foram analisados os documentos de $93,35 \%$ dos estados e municípios e cerca de $54 \%$ deles efetivaram a compra totalizando o valor de $\mathrm{R} \$ 148.571 .523,34^{4}$.

Para desenvolver ações interministeriais com vistas a dar suporte à implementação do Artigo 14 da Lei $11.947 / 2009^{5}$, foram instituídos pelo FNDE: 1) O Comitê Gestor, formado por representantes do Governo Federal por meio da Portaria no 450 de 2010 e 2) O Grupo Consultivo com a participação de representantes da sociedade civil, além dos representantes do Conselho Nacional de Secretários de Estados da Educação (CONSED) e a União Nacional dos Dirigentes Municipais de Educação (UNDIME), com fins de assessorar o Comitê Gestor.

Essa Lei ${ }^{5}$ também estabelece uma nova composição para os Conselhos de Alimentação Escolar, alterando para contemplar mais representantes das entidades de docentes, discentes ou trabalhadores na área de educação, indicados pelos respectivos órgãos de classe. A inovação se dá com a abertura à participação de qualquer outro profissional da educação, para além dos professores; abre a possibilidade da participação dos discentes que só poderão ser indicados e eleitos quando forem maiores de 18 anos ou emancipados; e amplia a participação da representação das entidades civis organizadas, excluindo a 
participação dos representantes do Legislativo, pelo motivo de que esse setor já tem como função precípua a fiscalização dos órgãos públicos.

Em relação à evolução do volume de recursos financeiros executados e o número de alunos atendidos pelo PNAE ao longo do período de 2003 a 2010, de acordo com a Tabela 1, observase que, em 2003, o Programa executou um total de 954,2 milhões de reais para atender $37,3 \mathrm{mi}$ lhões de alunos, ao passo que em 2010, o total de recursos passou a ser de 3 bilhões de reais (acréscimo de $317,9 \%$ ) para um total de 45,6 milhões de alunos atendidos (acréscimo de 122,3\% ou de $8,3$ milhões de alunos $)^{4}$.

No período de 2003 a 2011, houve importante aumento dos valores per capita transferidos pelo FNDE aos Estados, municípios e DF. Em 2003, o FNDE passou a assumir a alimentação escolar no ensino infantil (creches), repassando recursos de forma diferenciada para essa modalidade de ensino. Nos anos posteriores foi aumentando significativamente os valores per capita para creches, escolas indígenas e quilombolas. Destaca-se que a Portaria Interministerial $n^{\circ}$ 17/2007 criou o Programa Mais Educação que aumenta a oferta educativa nas escolas públicas por meio de atividades optativas como acompanhamento pedagógico, meio ambiente, esporte e lazer, direitos humanos, cultura e artes, cultura digital, prevenção e promoção da saúde, educomunicação, educação científica e educação econômica. Com isso o PNAE passou a repassar um per capita maior para os alunos que aderem ao Programa, com a exigência de que as EEx devem ofertar 3 refeições ao dia para esse alunos ${ }^{23}$.

A partir de 2007, com o objetivo de ampliar e garantir a melhoria da execução do PNAE, o FNDE estabeleceu parceria com Instituições Federais de Ensino Superior e construiu os Centros Colaboradores em Alimentação e Nutrição Escolar (CECANE), que são centros de ensino, pesquisa e extensão dessas instituições, atuantes nas cinco regiões geográficas brasileiras. Atualmente, são oito Cecanes atuantes no Brasil: Universidade Federal da Bahia, Universidade Federal de Ouro Preto, Universidade Federal do Rio Grande do Sul, Universidade Federal do Paraná, Universidade Federal de Santa Catarina, Universidade Federal de Goiás, Universidade Federal de São Paulo e Universidade de Brasília (UnB). Nesta mesma direção, também foram desenvolvidos projetos específicos como: a) Curso técnico de alimentação escolar para alunos do ensino médio na Bahia; b) projeto educando com a horta escolar e gastronomia com o Centro de Excelên- cia em Turismo e Gastronomia da UnB; c) formação em alimentação escolar para educadores do campo - UnB.

Ainda nesta parceria, foi criada a Rede Brasileira de Alimentação e Nutrição do Escolar (REBRAE) como um instrumento de integração e disseminação das ações realizadas nas escolas públicas brasileiras. Além de servir de apoio ao PNAE/FNDE, a REBRAE facilita o acesso e o intercâmbio de informações sobre o Programa junto aos estados, prefeituras, sociedade civil, poder judiciário e órgãos fiscalizadores, além de articular-se com outras redes, fóruns e associações nacionais e internacionais desta área ${ }^{24}$.

Ressalta-se ainda que, em função da experiência exitosa no campo da política nacional de alimentar escolar, a partir de 2003, o governo brasileiro começou a trabalhar intensamente no sentido de viabilizar o apoio ao desenvolvimento de Programas de Alimentação Escolar no âmbito da América Latina, Caribe, África e Ásia. Para tanto, em julho de 2005, o FNDE, assinou um Memorando de Entendimento com a FAO e o PMA com o objetivo de estabelecer um regime de colaboração/cooperação para a implantação de programas similares ao PNAE brasileiro em países em desenvolvimento. A partir daí iniciou com ações em Angola, São Tomé e Príncipe, Cabo Verde e Moçambique e Haiti. Em 2011, por influência do Brasil, foi criado o Centro de Excelência de Combate à Fome, sediado no Brasil, um órgão do PMA, que atua em vários países da África, Ásia, América Latina e Caribe. Além disso, o FNDE realiza cooperação efetiva em 8 países da América Latina e Caribe, por meio da FAO e da Agência Brasileira de Cooperação (ABC). O objetivo dessa cooperação é assessorar os países solicitantes na elaboração e implantação de programas nacionais de alimentação escolar sustentáveis, com base no programa brasileiro.

\section{Considerações finais}

De acordo com dados estatísticos oficiais, no período de 1995 a 2010, observa-se uma importante ampliação do PNAE, tanto em termos de alocação de recursos financeiros, cobertura populacional e estratégias operacionais, bem como em sua concepção ou ressignificação como política pública ou programa social em alimentação e nutrição do escolar no contexto da sociedade brasileira.

No percurso relatado, o PNAE deixa de ser concebido pelo gestor federal como um progra- 
ma, simplesmente, de caráter de suplementação alimentar ou assistencial, destinado inicialmente aos pré-escolares ( 5 a 6 anos) e aos escolares ( 7 a 14 anos) do primeiro grau, matriculados nos estabelecimentos de ensino público, por meio do fornecimento de uma refeição de valor nutricional equivalente a até $15 \%$ das recomendações nutricionais diárias durante o ano letivo.

Sobretudo, a partir de 2003, a Coordenação Geral do PNAE (CGPAE) deu início a uma série de estratégias visando à ressignificação do PNAE ou à reestruturação dos seus objetivos precípuos, diretrizes e das suas estruturas técnico-operacionais. A partir de 2009, o PNAE ousa ser um programa de alimentação escolar saudável para o universo da rede pública de educação básica e de jovens e adultos e também ousa estabelecer que no mínimo $30 \%$ dos repasses do PNAE sejam investidos na aquisição de produtos da agricultura familiar. Ou seja, a partir de então, obedecendo aos anseios norteadores das políticas públicas e dos movimentos sociais de caráter universal, o PNAE passou a incorporar em suas estratégias técnico-operacionais de execução junto aos estados e municípios (entidades executoras do programa) os seguintes princípios para a gestão e a execução da alimentação escolar: equidade, participação social, universalidade, sustentabilidade/ continuidade, compartilhamento de responsabilidades, direito humano à alimentação adequada e respeito aos hábitos e tradições regionais.

Os limites e as possibilidades de consecução destes objetivos e princípios delineados para a gestão e execução do PNAE são múltiplos e complexos. Envolvem fronteiras com distintos obstáculos (individual/local, geográfico/natural, econômico/social, político/ideológico, por exemplos) que podem facilitar ou dificultar a transposição ou passagem efetiva de um PNAE de caráter suplementar/assistencialista para um PNAE de caráter universal, equânime, participativo, integrador, educacional, sustentável e saudável. 


\section{Referências}

1. Pipitone MAP, Ometto AMH, da Silva MV, Sturion GL, Furtuoso MCO, Oetterer M. Atuação dos conselhos municipais de alimentação escolar na gestão do Programa Nacional de Alimentação Escolar. Rev Nutr 2003; 16(Supl. 2):143-154.

2. Sturion GL, Silva MV, Ometto AMH, Furtuoso, Pipitonne MAP. Fatores condicionantes da adesão dos alunos ao Programa de Alimentação Escolar no Brasil. Rev Nutr 2005; 18(Supl. 2):167-81.

3. Santos LMP, Santos SMC, Santana LAA, Henrique FCS, Mazza RPD, Santos LAS, Santos LS. Avaliação de políticas públicas de segurança alimentar e combate à fome no período 1995-2002. 4 - Programa Nacional de Alimentação Escolar. Cad Saude Publica 2007; 23(Supl. 11):2681-2693.

4. Brasil. Ministério da Educação (MS). Fundo Nacional de Desenvolvimento da Educação (FNDE). Alimentação Escolar. [acessado 2011 abr 18]. Disponível em: http://www.fnde.gov.br/

5. Brasil. Lei no 11.947 de 16 de junho de 2009. Dispõe sobre o atendimento da alimentação escolar e do Programa Dinheiro Direto na Escola aos alunos da educação básica. Diário Oficial da União 2009; 16 jun

6. Brasil. Resolução/CD/FNDE no 38 de 16 de julho de 2009. Dispõe sobre o atendimento da alimentação escolar aos alunos da educação básica no Programa Nacional de Alimentação Escolar (PNAE). Diário Oficial da União 2009; 16 jun.

7. Conselho Federal de Nutricionistas (Brasil). Resolução no 358 de 18 de maio de 2005. Dispõe sobre as atribuições do nutricionista no âmbito do Programa de Alimentação Escolar (PAE) e dá outras providências. [documento da Internet]. [acessado 2011 abr 18]. Disponível em: http://www.cfn.org.br/ novosite/pdf/res/2005/res358.pdf

8. Conselho Federal de Nutricionistas (Brasil). Resolução no 465 de 25 de agosto de 2010. Dispõe sobre as atribuições do nutricionista, estabelece parâmetros numéricos mínimos de referência no âmbito do Programa de Alimentação Escolar (PAE) e da outras providências. [acessado 2011 abr 18]. Disponível em: http://www.cfn.org.br/novosite/arquivos/Resol-CFN-465-atribuicao-nutricionistaPAE.pdf

9. Brasil. Ministério da Saúde (MS). Portaria interministerial no 1.010 de 8 de maio de 2006. Institui as diretrizes para a promoção da alimentação saudável nas escolas de educação infantil, fundamental e nível médio das redes públicas e privadas, em âmbito nacional. Diário Oficial da União 2006; 9 maio.

10. Coimbra M, Meira JFP, Starling MBL. Comer e apren der: uma história da alimentação escolar no Brasil Belo Horizonte: MEC, INAE; 1982.

11. L'Abbate S. As Políticas de Alimentação e Nutrição no Brasil: I. Período de 1940 a 1964. Rev Nutr 1988 1(Supl. 2):87-138

12. Vasconcelos FAG. Os Arquivos Brasileiros de Nutrição: Uma Revisão sobre Produção Científica em Nutrição no Brasil (1944 a 1968). Cad Saude Publica 1999; 15(Supl. 2):303-316.
13. Vasconcelos FAG. Combate à fome no Brasil: uma análise histórica de Vargas a Lula. Rev Nutr 2005; 18(Supl. 4):439-457.

14. Castro J. Geografia da Fome (o dilema brasileiro: pão ou aço). 10 a Edição revista. Rio de Janeiro: Antares, Achiamé; 1980.

15. Brasil. Ministério da Saúde (MS). Instituto de Alimentação e Nutrição (INAN). 1976. Programa Nacional de Alimentação e Nutrição - PRONAN: 1976 1979. Brasília: MS; 1976. (Documento Técnico 06)

16. Schmitz BAS, Heyde MEDV, Cintra IP, Franceschini S, Taddei JAC, Sigulem D. Políticas e Programas Governamentais de Alimentação e Nutrição no Brasil e sua Involução. Cad Nutr 1997; 13:39-54.

17. Brasil. Constituição (1988). Constituição da República Federativa do Brasil. Brasília, DF: Senado Federal; 1988.

18. Brasil. Lei no 8.913 de 12 de julho de 1994. Dispõe sobre a municipalização da merenda escolar [Internet]. 1994 [acessado $2012 \mathrm{fev}$ 22]. Disponível em: http://www.planalto.gov.br/ccivil_03/Leis/L8913. htm.

19. Brasil. Medida Provisória n. ${ }^{\circ} 1.784$ de 14 dezembro de 1998. Dispõe sobre o repasse de recursos financeiros do Programa Nacional de Alimentação Escolar, institui o Programa Dinheiro Direto na Escola, e dá outras providências. Diário Oficial da União 1997; $15 \mathrm{dez}$

20. Brasil. Medida Provisória n. ${ }^{\circ} 1.979-19$ de 02 de junho de 2000. Dispõe sobre o repasse de recursos financeiros do Programa Nacional de Alimentação Escolar, institui o Programa Dinheiro Direto na Escola, e dá outras providências. Diário Oficial da União 2000; 03 jun.

21. Brasil. Ministério do Desenvolvimento Social Combate à Fome. Programa Fome Zero. [acessado 2011 abr 18]. Disponível em: http://www.fomezero. gov.br/

22. Fundo Nacional de Desenvolvimento da Educação (Brasil). Resolução no 38 de 23 de agosto de 2004. Estabelece critérios para execução do PNAE. Diário Oficial da União 2004; 23 ago.

23. Brasil. Portaria Normativa Interministerial $n^{\circ} 17 \mathrm{de}$ 24 de abril de 2007. Institui o Programa Mais Educação que visa fomentar a educação integral de crianças, adolescentes e jovens, por meio do apoio a atividades sócio-educativas no contraturno escolar. Diário Oficial da União 2007; 26 abr.

24. Rede Brasileira de Alimentação e Nutrição do Escolar. [página na Internet]. [acessado 2012 abr 05]. Disponível em: http://www.rebrae.com.br/

Artigo apresentado em 03/01/2013

Aprovado em 06/01/2013

Versão final apresentada em 10/01/2013 